\title{
Curriculum for small-bowel capsule endoscopy and device- assisted enteroscopy training in Europe: European Society of Gastrointestinal Endoscopy (ESGE) Position Statement
}

\section{(द) ESGE}

Authors

Reena Sidhu ${ }^{1}$, Stefania Chetcuti Zammit ${ }^{1}$, Peter Baltes ${ }^{2}$, Cristina Carretero ${ }^{3}$, Edward J. Despott ${ }^{4}$, Alberto Murino ${ }^{4}$, Xavier Dray ${ }^{5}$, David S. Sanders ${ }^{1}$, Martin Keuchel ${ }^{2}$, Evelien Dekker ${ }^{6}$, James E. East ${ }^{7,8}$, Gavin Johnson ${ }^{9}$, Pedro Pimentel-Nunes ${ }^{10,11,12}$, Marianna Arvanitakis ${ }^{13}$, Thierry Ponchon ${ }^{14}$, Mario Dinis-Ribeiro ${ }^{10,11}$, Raf Bisschops ${ }^{15}$

Institutions

1 Academic Department of Gastroenterology and Hepatology, Sheffield Teaching Hospitals NHS Trust, Sheffield, UK

2 Clinic for Internal Medicine, Bethesda Krankenhaus Bergedorf, Hamburg, Germany

3 Gastroenterology Department, University of Navarra Clinic, Pamplona, Spain

4 Royal Free Unit for Endoscopy, The Royal Free Hospital and University College London (UCL) Institute for Liver and Digestive Health Hampstead Campus, London, UK

5 Endoscopy Unit, Hôpital Saint-Antoine, Assistance Publique-Hôpitaux de Paris and Sorbonne Université, Paris, France

6 Department of Gastroenterology and Hepatology, Academic Medical Centre, Amsterdam, The Netherlands

7 Translational Gastroenterology Unit, Nuffield Department of Medicine, Experimental Medicine Division, John Radcliffe Hospital, University of Oxford, Oxford, UK

8 Oxford NIHR Biomedical Research Centre, University of Oxford, Oxford, UK

9 University College London Hospitals, London, UK

10 Gastroenterology Department, Portuguese Oncology Institute of Porto, Porto, Portugal

11 Center for Research in Health Technologies and Information Systems (CINTESIS), Faculty of Medicine, University of Porto, Porto, Portugal

12 Surgery and Physiology Department, Faculty of Medicine, University of Porto, Porto, Portugal

13 Department of Gastroenterology, Hepatopancreatology and Digestive Oncology Erasme University Hospital, Brussels, Belgium

14 Gastroenterology Division, Hôpital Edouard Herriot, Lyon, France

15 Department of Gastroenterology and Hepatology, Catholic University of Leuven (KUL), TARGID, University Hospitals Leuven, Leuven, Belgium
Bibliography

DOI https://doi.org/10.1055/a-1185-1289

Published online: 17.6.2020 | Endoscopy 2020; 52: 669-686

(c) Georg Thieme Verlag KG Stuttgart · New York

ISSN 0013-726X

Corresponding author

Reena Sidhu, MD , Academic Department of

Gastroenterology, Royal Hallamshire Hospital, Sheffield

Teaching Hospitals NHS Trust, Glossop Road, Sheffield,

S10 2SB, United Kingdom

reenasidhu@nhs.net

\section{MAIN RECOMMENDATIONS}

The European Society of Gastrointestinal Endoscopy (ESGE) has recognized the need to formalize training in small-bowel endoscopy across European centers. The following criteria and framework for training in small-bowel capsule endoscopy (SBCE) and device-assisted enteroscopy (DAE), which aim to provide uniform and high quality training to ensure that small-bowel endoscopists are competent to operate independently, are based on the current literature and experience of experts in the field. Three main areas are covered: skills required prior to commencing training in small-bowel endoscopy; structured training for trainees to become independent endoscopists; and ways of ensuring competence is achieved.

1 Centers providing training in SBCE should perform a minimum of 75-100 SBCEs/year.

2 Experience in bidirectional endoscopies is desirable for structured training in SBCE.

3 SBCE courses should consist of at least $50 \%$ hands-on training and cover information on technology, indications and contraindications for SBCE, pathologies that can be encountered on SBCE, and standard terminology that should be used during reporting of SBCE. An SBCE course should be completed prior to achieving competence in SBCE reporting. 
4 Competence in SBCE can be assessed by considering a minimum of 30 SBCEs. Direct Observation of Procedural Skills, short SBCE videos, and multiple-choice questions can be useful to assess improvement in the skills of trainees.

5 Centers offering training in DAE should aim to carry out at least 75 DAEs/year, should have direct links with an SBCE service, and should allow regular discussion of cases at a radiology small-bowel MDT. Training centers with lower numbers are encouraged to offer training by "buddyingup" with other centers, or using mentoring systems.

6 DAE trainees must be independent in bidirectional endoscopies and have experience in level 1 polypectomy prior to commencement of training. They should also be competent in reviewing SBCEs.
7 Training in DAE should be structured with a minimum of 75 procedures, including 35 retrograde DAEs, with therapeutic procedures undertaken in at least $50 \%$ of the DAEs performed. Training should cover the indications, contraindications, complications including prevention, and technicalities of the DAE procedure; formal evaluation should follow. DAE trainees must acquire skills to independently manage and advise on small-bowel pathology following DAE procedures.

$8 \mathrm{It}$ is highly recommended that international societies develop online modules and courses on DAE, which are currently lacking across Europe.

\section{SOURCE AND SCOPE}

This Position Statement is an official statement of the European Society of Gastrointestinal Endoscopy (ESGE). It provides recommendations for a European core curriculum aimed at providing high quality training in smallbowel capsule endoscopy and device-assisted enteroscopy. The recommendations presented are based on a consensus among endoscopists considered to be experts in the field of small-bowel endoscopy who are involved in training and training courses in Europe.

\section{Introduction}

The European Society of Gastrointestinal Endoscopy (ESGE) has identified an increasing demand for endoscopic therapeutic interventions, along with an increased complexity in diagnostic procedures. However, there is a lack of guidance on the specifications of training for some complex endoscopic procedures. These situations present a growing need for specific training in advanced endoscopic procedures [1]. Consequently, the ESGE has recently created a working group focused on developing a curriculum for minimum standards and training in specific endoscopic procedures, particularly interventional procedures that require additional training beyond the core curriculum provided in each country. Furthermore, advanced endoscopic procedures such as small-bowel capsule endoscopy (SBCE) and device-assisted enteroscopy (DAE) are not always included in core training programs.

In 2015, among 64 adult gastrointestinal (GI) programs in the USA, $38 \%$ reported having a formal GI capsule endoscopy module and $27 \%$ required attendance at a hands-on course [2]. Read et al. [3] contacted 168 fellowship program directors 3 years later and concluded that SBCE training was universally available, being compulsory for fellows in $84.8 \%$ of cases. On the other hand, DAE was available in $86.4 \%$ of training pro- grams, but not all trainees were required to undergo formal DAE training (12.1\% - 22.9\%). Sidhu et al. [4] conducted a survey of trainee gastroenterologists in the UK in 2008. They concluded that $88 \%$ of trainees were interested in learning about SBCE; however, only $38 \%$ had SBCE available in their units and an even smaller number of trainees (13\%) had ever reported an SBCE study [4].

SBCE has become the first-line investigation for patients with suspected small-bowel pathology, particularly in the context of obscure GI bleeding. Its non-invasive nature and good safety profile make it the investigation of choice for both physicians and patients. It is included in the algorithm for investigation of small-bowel pathologies, such as inflammatory bowel disease, and for the detection of the complications of celiac disease [5].

Despite the increasing demand for SBCE [6], training standards in SBCE are lacking and vary across European centers. It is crucial to recognize the need for standardized training programs in SBCE to mirror its rising demand. This can only be ful-

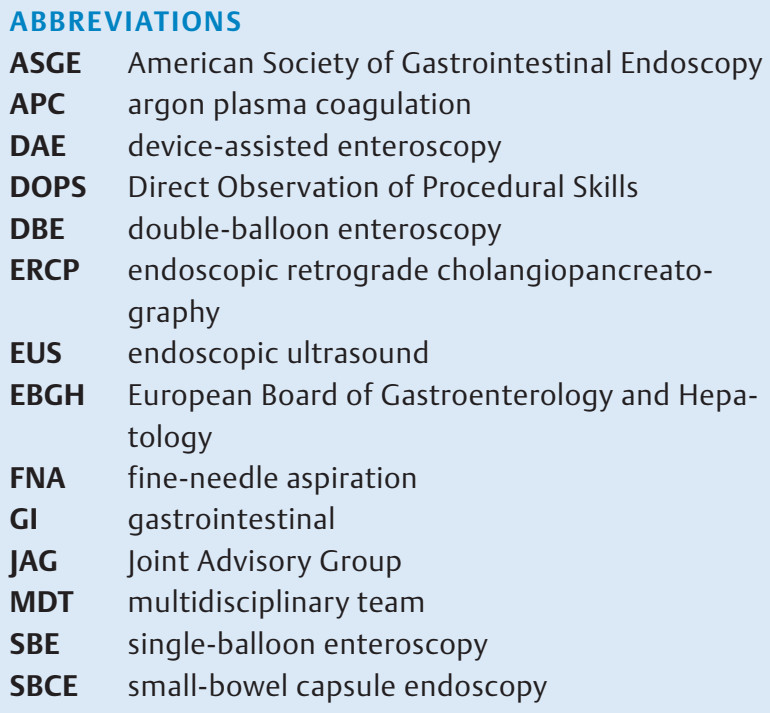


filled by introducing high quality training to gastroenterologists who are interested in setting up an SBCE service. Training goes beyond simply reading and reporting a video, and must also include the formulation of an appropriate management plan for patients as part of the investigation of small-bowel pathology. Previous small studies have already demonstrated the positive impact training can have on the delineation of pathology on SBCE $[7,8]$. However, to date, the number of SBCEs needed to obtain competence has not been defined.

The first DAE platform to be introduced into clinical practice was double-balloon enteroscopy (DBE), as reported by Yamamoto et al. in 2001 [9]. Since then, other platforms, namely single-balloon enteroscopy (SBE) [10] and more recently spiral enteroscopy, have been developed [11]. These DAE platforms vary in technique. SBE and DBE rely on the same basic principles: the use of an overtube and traction modalities to help advance and anchor the enteroscope within the small bowel. Spiral enteroscopy allows the use of a spiral overtube and its spiral movement to pleat the bowel onto the enteroscope.

Although it is recommended that training in DAE should be undertaken at an advanced stage of endoscopy training, this varies according to different European endoscopy centers. Trainees are also exposed to different diagnostic and therapeutic case loads of varying complexity. In addition to being technically competent in carrying out DAEs, an increasing need is recognized for trainees to be able to plan appropriately for DAE and to be involved in the management planning of patients with small-bowel disorders following DAE.

We, as the small-bowel Curriculum Working Group, aimed to develop training standards on an evidence-based level and with input from experts in small-bowel endoscopic techniques where evidence is lacking. These will be similar to the established training infrastructure that has already been developed for other endoscopic procedures.

The recommendations presented in this curriculum ( $\triangleright$ Table 1 and $\$$ Table 2 ) are based on a consensus among SBCE and DAE experts who are involved in small-bowel endoscopy training.

\section{Aims}

The primary aims of this curriculum are:

- to develop a European core curriculum for SBCE and DAE training across Europe

- to define the baseline skills and competence that an endoscopist considering offering SBCE and DAE training should have acquired

- to set a framework for standardization of training in SBCE and DAE for trainees wishing to pursue advanced enteroscopy.

The secondary aims are:

- to increase awareness about the skills and difficulties that are encountered during the performance of SBCE and DAE

- to encourage and support individual endoscopy departments to develop training in SBCE and DAE that is in line with ESGE recommendations.
- Table 1 List of recommendations for training in small-bowel capsule endoscopy (SBCE).

\section{Skills/competence to start training in SBCE}

Experience in $\mathrm{Gl}$ endoscopy is desirable for structured training in SBCE 2 Training

At least one faculty member of a structured SBCE course should have completed and reported more than 500 procedures

At least one faculty member of a structured SBCE course should have experience in DAE

A service providing SBCE training should perform a minimum number of $75-100$ capsule endoscopies per year

Experience in SBCE may be helpful for a hands-on course

Structured SBCE courses should impart a proper knowledge of technology, procedure, indications, contraindications, normal anatomy including variants, common findings, and differential diagnosis, as well as reporting that includes the use of standard terminology

Structured SBCE courses should consist of at least $50 \%$ hands-on training with reading and interpreting video cases. Hands-on training SBCE videos should include the most relevant findings

Structured SBCE courses should be open for endoscopy nurses who pre-read SBCE (in European countries where this is applicable)

\section{Knowledge and maintaining competence}

Before credentialing competence in SBCE reporting, a structured training course/program should be completed

Competence in SBCE should be assessed. Where no structured assessment process is established, a minimum number of 30 SBCEs analyzed under supervision may serve as a parameter to assess competency

Direct Observation of Procedural Skills can be useful to assess improvement in the skills of trainees

Test videos or short video files can be useful to assess improvement in the skills of trainees

Multiple-choice questions can be useful to assess improvement in the knowledge of trainees

GI, gastrointestinal; DAE, device-assisted enteroscopy.

\section{Methods}

The multistep process for developing performance measures has been described previously [12]. After the first meeting held in February 2018, detailed literature searches were performed that yielded limited evidence for training in both SBCE and DAE. Results were discussed and appropriate statements for future voting were phrased. Every participant was required to comment on all the proposed statements during teleconferences. All statements that were identified by this process were structured using the PICO framework (where P stands for Population/Patient; I for Intervention/Indicator; C for Comparator/ Control; and O for Outcome) to inform searches for available evidence to support the statements. The PICO and clinical statements were adapted and/or excluded during the iterative rounds of comments and suggestions from the extended working group members during the Delphi process. 
- Table 2 List of recommendations for training in device-assisted enteroscopy (DAE).

\section{Skills/competence to start training in DAE}

For the purpose of DAE training, all centers offering training should aim to carry out a minimum of 75 DAEs per year

All DAE training centers should have direct links to an SBCE service

DAE trainers should be competent in SBCE

The diagnostic yield and complication rates of DAE trainers should be regularly audited, and quality indicators monitored locally

Trainees who wish to undertake DAE training must be equipped with basic endoscopy skill-sets that should include independent practice in both gastroscopy and colonoscopy and experience of level 1 polypectomy (polyps less than $1 \mathrm{~cm}$ in size)

Trainees wishing to undertake DAE should also be trained in reading SBCES

Within DAE training, trainees who wish to undertake ERCP procedures using DAE must be competent at ERCP and diagnostic DAE first

\section{Training}

Training in DAE should be structured with a minimum of 75 procedures, including 35 retrograde DAEs

DAE training centers should have a radiology small-bowel MDT where small-bowel cases can be discussed or incorporated into an existing framework

\section{Knowledge and maintaining competence}

It is highly recommended that international societies develop online modules and courses on DAE, which are currently lacking across Europe

Within the DAE training fellowship, basic procedural aspects, equipment check, and technique for the subtype of DAE should be covered with formal evaluation

Within DAE fellowships, the contraindications for DAE should be covered within the small-bowel cases encountered and by discussion at a radiology small-bowel MDT

During DAE training, either formal or informal evaluation (depending on country) needs to be completed for diagnostic and therapeutic procedures

DAE trainees should have the opportunity to perform therapeutic DAE (in a minimum of $50 \%$ of the total number of DAEs performed)

Within DAE fellowships, trainees must have the ability to recognize and deal with complications of DAE and their prevention

Within DAE fellowships, trainees must acquire skills to be able to independently advise on and manage small-bowel pathology post DAE

International societies are encouraged to set up DAE courses for trainees to attend (no regular set up at present) and to set up a formal or informal "buddying-up" or mentoring system for DAE units to offer training to other gastroenterologists in their country

SBCE, small-bowel capsule endoscopy; ERCP, endoscopic retrograde cholangiopancreatography; MDT, multidisciplinary team.
The core group decided to additionally invite experts in SBCE and DAE who were providing training in these techniques to vote on the statements and provide their comments if necessary.

In total, 23 working group members participated in three rounds of voting to agree on the statements in predefined domains, which are discussed below. The agreement that is given for the different statements refers to the last voting round in the Delphi process. A statement was accepted if at least $80 \%$ agreement was reached. If such agreement was not achieved in rounds one or two, the core working group members discussed the statements during teleconferences and rephrased the statements to reflect the comments of the voting group. The rephrased statements were then included in the next voting round. To ensure consistency of the voting process, some statements that had achieved a consensus of more than $80 \%$ in the previous voting round were included again in the next round.

\section{Training in small-bowel capsule endoscopy (SBCE)}

\section{Skills/competence to start training in SBCE}

\section{RECOMMENDATION}

Experience in $\mathrm{Gl}$ endoscopy is desirable for structured training in SBCE.

Level of agreement $92 \%$.

It has been shown that baseline scores for the correct evaluation of short SBCE test videos correlate with previous experience in gastroscopy and colonoscopy [13]. Endoscopic experience also correlated with improved polyp detection and size estimation at SBCE in an animal model [14]. In this study, 10 gastroenterology trainees were better at determining the gastric emptying time $(P=0.01)$ and more likely to record true positives compared with five medical students $(P=0.04)$. They were also less likely to record false positives $(P=0.005)$ and more likely to reach the correct diagnosis (odds ratio 3.6, confidence interval $1.8-7.4 ; P=0.001$ ) [4]. Gl physiologists without endoscopic experience can also be successfully trained to review SBCEs [15].

\section{Providing training in SBCE}

\section{RECOMMENDATION}

At least one faculty member of a structured SBCE course should have completed and reported more than 500 procedures.

Level of agreement $90 \%$. 
It is important that at least one faculty member of a structured SBCE course has had experience with more than 500 SBCEs. Studies show that SBCE reviewers with a considerable experience in SBCE perform better. Experts with experience of more than 400 SBCE studies performed better in size estimation of lesions in a porcine model [16]. In a multicenter study on European courses, participants had better scores for correct assessment of short video clips if they had analyzed more than 100 SBCEs before the course, with 12 delegates already having had this level of experience [13]. Additionally, experience with a bigger case load can help to improve the familiarity with rare small-bowel pathologies.

\section{RECOMMENDATION}

At least one faculty member of a structured SBCE course should have experience in DAE.

Level of agreement $84 \%$.

Appropriate referral for DAE, depending on SBCE findings, is a key performance parameter defined by the ESGE Quality Improvement Initiative committee [17]. Despite the lack of literature in this area, it is important that at least one faculty member is competent in performing DAE, and is familiar with its limitations and with the small-bowel findings encountered during DAE.

\section{RECOMMENDATION}

A service providing SBCE training should perform a minimum number of 75-100 capsule endoscopies per year. Level of agreement $100 \%$.

In the UK where SBCE accreditation is imminent, the Joint Advisory Group (JAG) for training in small-bowel endoscopy recommends that 50 procedures are undertaken prior to assessment of competency, regardless of previous endoscopic experience. Although the emphasis is on proficiency rather than numbers, the group also suggests that Direct Observation of Procedural Skills (DOPS) may provide further evidence on the numbers of SBCEs required to achieve competency [18]. For the purpose of this guideline, a consensus was reached of a minimum of 75-100 capsules per year for a center to be able to offer SBCE training.

\section{RECOMMENDATION}

Experience in SBCE may be helpful for a hands-on course. Level of agreement $100 \%$.
Delegates for courses on training in SBCE have been shown to perform better if they have previous experience in reviewing SBCEs. Trainees who had previous experience with 11 or more SBCE studies before attending a structured hands-on course had higher baseline test scores for short SBCE videos in a multicenter study [13]. Competency training was assessed following completion of SBCE training using the Capsule Competency Test. Trainees with a greater capsule reviewing experience had better scores [8].

\section{RECOMMENDATION}

Structured SBCE courses should impart a proper knowledge of technology, procedure, indications, contraindications, normal anatomy including variants, common findings, and differential diagnosis, as well as reporting that includes the use of standard terminology.

Level of agreement $100 \%$.

Recently an international core curriculum for SBCE training courses defined in detail relevant topics for lectures and hands-on training [19]. Delegates attending hands-on training courses have shown improvement in providing the correct diagnosis and classification of small-bowel pathology [13]. The proper use of terminology whilst reporting SBCEs is imperative and should be emphasized during these courses. Reporting should be in line with the Capsule Endoscopy Standard Terminology that has been published [20]. The aim of this was to improve uniformity in the interpretation and reporting of small-bowel pathology [21]. Finally, performance measures for SBCE, as proposed by the ESGE recently [17], should be addressed in a structured SBCE course.

\section{RECOMMENDATION}

Structured SBCE courses should consist of at least $50 \%$ hands-on training with reading and interpreting video cases. Hands-on training videos should include the most relevant findings.

Level of agreement $100 \%$.

A detailed European curriculum for a structured SBCE handson course, proposed by a group of experts and recently published, suggested $50 \%$ theoretical content and 50\% hands-on training [19]. Improved diagnostic skills have been demonstrated by trainees following their attendance as delegates at structured SBCE courses with $50 \%$ hands-on training [13].

In view of time constraints, only a limited number of videos with small-bowel pathology can be used for teaching purposes during a course. A significant proportion of real-life videos do not detect pathology. Additionally, some lesions such as angioectasias are more frequently encountered than others. As a result, there should be a careful selection of videos to 
include significant lesions such as ulcers, strictures, polyps, and various tumors, but also rarer pathologies, such as diverticula, despite their low incidence in current practice. Furthermore, recognition of variants of normal should be included in hands-on training SBCE videos.

A lower accuracy in SBCE reading for trainees compared with experts has been noted for certain pathologies, such as tumors, venous abnormalities, ulcers, and villous atrophy [21,22]. Delineation of small-bowel pathology also varies according to the prominence of lesions and across different pathologies, highlighting the need to cover different pathologies during structured SBCE courses [21,23].

\section{RECOMMENDATION}

Structured SBCE courses should be open for endoscopy nurses who pre-read SBCE videos (in European countries where this is applicable).

Level of agreement $95 \%$.

Nurses in many centers are pre-reading SBCE videos. A recent meta-analysis has shown a similar pooled proportion of findings reported by nurses with prior endoscopic experience in comparison with physicians ( $86 \%$ and $89 \%$, respectively) [24]. A prospective multicenter study found no significant difference in the improvement in scores reflecting performance and delineation of small-bowel pathology between nurses and physicians during hands-on SBCE courses [13].

Furthermore, ESGE recommends the acceptance of qualified nurses and trained technicians as SBCE pre-readers, with the supervising physician being ultimately responsible for establishing a diagnosis [25]. In consequence, this recommendation implies the need for the inclusion of nurses in structured SBCE training courses.

\section{Knowledge and maintaining competence in SBCE}

\section{RECOMMENDATION}

Before credentialing competence in SBCE reporting, a structured training course/program should be completed. Level of agreement $100 \%$.

Structured SBCE training could be included in a GI fellowship curriculum. However, a recent US survey in third-year graduating fellows found that the curricular need for SBCE was met in only $42 \%$, in contrast to $100 \%$ for colonoscopy [26].

Additionally, participating in a structured hands-on course with a duration of at least 8 hours is recommended [19]. Attending an 8-hour hands-on course, together with supervised SBCE reading in a post-fellowship setting, is also recommended by the American Society of Gastrointestinal Endoscopy (ASGE) [27].

Structured e-learning with online assessment is an alternative option for training in SBCE, in addition to supervised read- ing and reporting of SBCE videos. An e-learning platform for accreditation in SBCE has been developed in the UK. This is part of the training pathway for accreditation in SBCE comprising of e-learning modules, capsule courses, and hands-on training, which is soon to be launched [28]. A pan-European online SBCE learning platform is desirable but not currently available.

\section{RECOMMENDATION}

Competence in SBCE should be assessed. Where no structured assessment process is established, a minimum number of 30 SBCEs analyzed under supervision may serve as a parameter to assess competency.

Level of agreement $95 \%$.

There was strong consensus that competency for SBCE should be achieved in a similar manner to attainment of competency for other endoscopic procedures. Based on expert opinion, a consensus was reached for the minimum number of SBCE procedures to be reported under supervision to assess competency. At least 30 SBCE videos analyzed under supervision may serve as a parameter to assess competency. The group of experts are aware that this number is an absolute minimum and that continuing supervision and quality assessment is strongly suggested.

A Korean group found the competency of Gl fellows improved when compared with experts after 11 SBCEs were reviewed (mean $\kappa$ coefficients improved from $>0.60$ to $>0.80$ after 11 SBCEs). Accordingly, 10 procedures were deemed to be sufficient to assess competence [29]. A European multicenter study found a plateau in the learning curve for SBCEs after 25 procedures [13]. The performance of fellows with less than 20 supervised SBCE readings was inferior to the performance of those who had read more than 20 SBCEs after a formalized training program [8]. In a recent American multicenter study, fellows enrolled in a structured SBCE training program achieved a mean score of 84 or better when they had interpreted at least 25 SBCEs [30].

The ESGE Quality Improvement small-bowel working group suggested 30-50 SBCE supervised readings [17]. The ASGE recommends a minimum of 20 procedures [27]. The curriculum of the European Board of Gastroenterology and Hepatology $(\mathrm{EBGH})$ requires $30 \mathrm{SBCE}$ procedures and 10 flexible enteroscopies for competence to be achieved [31]. German quality parameters for reimbursement of outpatient SBCE in obscure GI bleeding demand a minimum number of 25 reports and five full SBCE procedures, including pre-counseling, preparation of the hardware, and guidance of the patient through the process [32].

\section{RECOMMENDATION}

Direct Observation of Procedural Skills can be useful to assess improvement in the skills of trainees.

Level of agreement $84 \%$. 
The JAG on GI endoscopy of the Royal College of Physicians has agreed on detailed forms for documenting DOPS in SBCE, including the use of the patency capsule, in the UK [18]. To make the system more robust, current colonoscopy training criteria, established by JAG, require 20 formative DOPS to be filled in by a trainer (approximately 1 DOPS every 10 procedures performed), followed by four summative DOPS over the space of 1 month by a minimum of two trainers other than the primary trainer [18]. This minimizes subjective trainer bias and the risk of awarding completion of training to trainees who do not meet the established criteria. In other countries, this structured form of assessment is not generally available but can be easily adapted to assess trainees.

\section{RECOMMENDATION}

Test videos or short video files can be useful to assess improvement in the skills of trainees.

Level of agreement $95 \%$.

Short test videos have been successfully applied in the simple evaluation tool for capsule endoscopy training, the Capsule Competency Test, and an e-learning module to assess improvement in the skills of trainees $[8,13,33]$.

\section{RECOMMENDATION}

Multiple-choice questions can be useful to assess improvement in the knowledge of trainees.

Level of agreement $91 \%$.

Assessment by multiple-choice questions is a useful method of assessing trainees during SBCE training. An e-learning module on SBCE containing multiple-choice questions was offered to gastroenterology trainees and medical students to assess their learning. Both groups improved their results from a multiple-choice test, with trainees doing better than students before and after training was completed [33]. Another study that utilized the Capsule Competency Test also included multiplechoice questions as part of the assessment [8]. Multiple-choice questions can be valuable add-ons in the assessment of competency but should not be used as sole parameters.

- Fig. 1 summarizes training in SBCE.
- Gl endoscopy experience desirable

- One course faculty member with > 500 SBCE procedures

- One course faculty member with DAE experience

Structured course

- SBCE experience helpful before course

- Inclusion of all relevant aspects of SBCE

- $50 \%$ hands-on videos

- Videos with all relevant pathologies

- Access for endoscopy nurses

Training center

- Ongoing experience with 75-100 SBCEs/year

Assessment of competency recommended

- Structured SBCE course

- DOPS useful

- 30 supervised SBCE readings

- Test videos useful

- Multiple-choice questions useful

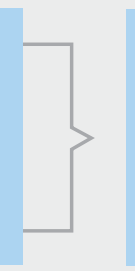

Skills/

competence

to start

training in

SBCE
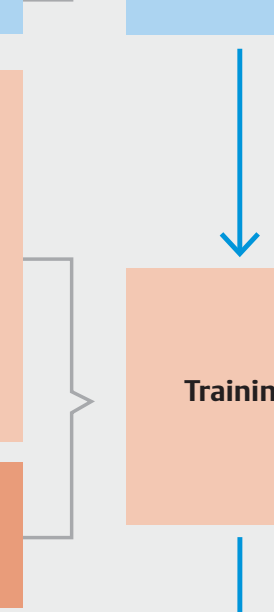

Training

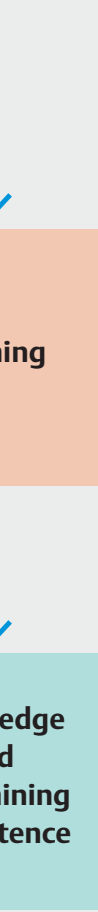

- Fig. 1 Diagram summarizing the ESGE training curriculum for small-bowel capsule endoscopy (SBCE).

GI, gastrointestinal; DAE, device-assisted enteroscopy; DOPS, Direct Observation of Procedural Skills.

\section{Training in device-assisted enteroscopy} (DAE)

\section{Skills/competence to start training in DAE}

\section{RECOMMENDATION}

For the purpose of DAE training, all centers offering training should aim to carry out a minimum of 75 DAEs per year.

Level of agreement $100 \%$.

There is no literature on the recommended number of DAEs per year that a center should be performing before it can offer training in DAE. Most experts agreed that the aim should be for 75 or more DAEs per year. A high case load of DAEs per year is important to ensure that an adequate number of procedures are being carried out in centers offering training. This will in 
turn increase the likelihood of centers being able to offer dedicated DAE training lists and help to improve the performance of trainees in the detection of varying small-bowel pathologies. It is recognized that DAE is a complex procedure and of varying difficulty. A high case load will also ensure that trainees are exposed to an adequate number of cases with varied pathology and complexity during their training period.

\section{RECOMMENDATION}

All DAE training centers should have direct links to an SBCE service.

Level of agreement $100 \%$.

The non-invasive nature of SBCE means that it is the first investigation that is carried out when small-bowel pathology is suspected. Visualization of the entire small bowel enables pathology to be localized in relation to the small-bowel transit and an antegrade or retrograde approach planned. This maximizes the chances of identifying any small-bowel pathology during DAE. Gay et al. [34] first described the methodology of determining the route of approach for DAE, according to SBCE findings in relation to small-bowel transit time. According to this study, if the pathology was encountered within the first $75 \%$ of the small-bowel transit (capsule transit time from ingestion to arrival at the lesion), an antegrade approach would be preferable. The positive predictive value of SBCE to make a correct indication for enteroscopy using this approach was $94.7 \%$ and the negative predictive value was $98.3 \%$. In another study by $\mathrm{Li}$ et al., the index of lesion location was calculated, which was defined as the time from the pylorus to the lesion as a percentage of the time from the pylorus to the ileocecal valve. A cutoff value of 0.6 was used. Patients underwent antegrade DBE if the index value was $\leq 0.6$ and retrograde DBE if the index value was $>0.6$. The accuracy of selecting the insertion route of DBE was $100 \%$ using this method [35].

Another important quality performance measure in DAE is the appropriate indication for DAE, which was recently described in the ESGE Quality Improvement performance measures for small-bowel endoscopy [17]. The positive and negative predictive values of DAE when preceded by positive SBCE are both high (94.7\% and $98.3 \%$, respectively) [34]. A meta-analysis comparing the yield of DAE and SBCE has demonstrated that the yield of the former is significantly higher after a positive SBCE, when compared with the yield after a negative SBCE [17]. The approach of carrying out DAE preceded by SBCE is favored wherever possible, as it will ensure that patients are not exposed to unnecessary risks related to DAE. Having access to the result of an SBCE can also help plan appropriately for therapeutic procedures, such as argon plasma coagulation (APC) in the case of angioectasias. DAE should only be carried out as the first investigation of choice in emergency situations, such as active small-bowel bleeding [17], using the antegrade approach first unless the patient is known to have a distal small-bowel lesion [25].
Some patients require a repeat $\mathrm{SBCE}$ following their $\mathrm{DAE}$ $[17,36]$. Having access to an SBCE service can facilitate this complementary strategy.

\section{RECOMMENDATION}

DAE trainers should be competent in SBCE.

Level of agreement $91.3 \%$.

There is no published literature on competence in SBCE and DAE performance. In view of its non-invasive nature, SBCE is generally the first procedure patients undergo prior to DAE [37]. The odds ratio of a positive DAE in patients with a positive SBCE prior to DAE has been shown to be much higher (1.79), when compared with DAE in all patients irrespective of the SBCE result [38]. SBCE can help characterize any pathology and determine if further investigation, such as dedicated small-bowel cross-sectional imaging, is needed prior to performing DAE. SBCE can help to plan appropriately for any DAE endotherapy.

\section{RECOMMENDATION}

The diagnostic yield and complication rates of trainers should be regularly audited, and quality indicators monitored locally.

Level of agreement $100 \%$.

Auditing complication rates of trainers within a DAE training center will ensure that the quality of the training delivered reflects high quality DAE standards within the training unit.

The complication rate of DAE varies from $0.8 \%$ for diagnostic procedures to $5 \%$ for therapeutic procedure [39-49]. In the recent publication by ESGE on quality performance indicators in small-bowel endoscopy, a threshold standard was set for the accepted rate of complications for DAE. The rates of severe complications resulting from diagnostic DAE and therapeutic DAE, and the rate of post-procedure pancreatitis should not exceed $1 \%, 5 \%$, and $0.3 \%$, respectively [17].

Within subtypes of DAE, no difference in adverse events has been reported between DBE and SBE [50,51], with complications including bleeding, perforation, and pancreatitis. The risk of post-procedure pancreatitis increases with the duration of the procedure and the depth of endoscope insertion [5256], and may be reduced by minimizing mechanical stress during insertion and withdrawal, and avoiding balloon inflation within the proximal duodenum [48]. It is anticipated that technical measures to reduce complications will be taught through DAE hands-on training.

Deriving evidence from complications following polypectomy during colonoscopy and endoscopic submucosal dissection, it has been shown that the complication rate is higher in endoscopists with a low-volume case load [57-61]. 


\section{RECOMMENDATION}

Trainees who wish to undertake DAE training must be equipped with basic endoscopy skill-sets that should include independent practice in both gastroscopy and colonoscopy and experience of level 1 polypectomy (polyps less than $1 \mathrm{~cm}$ in size).

Level of agreement $94.7 \%$.

It is recognized that DAE is a complex procedure and that it can prove challenging even to advanced endoscopists. It is therefore recommended that trainees be independent in performing both gastroscopy and colonoscopy and have considerable experience in both diagnostic and therapeutic procedures before embarking on specialist training in DAE [62]. This is also true for other advanced endoscopic procedures. Deriving evidence from literature relating to other complex endoscopies, the ASGE recommends that trainees are proficient in standard gastroscopy prior to commencing training in endoscopic ultrasound (EUS) and endoscopic retrograde cholangiopancreatography (ERCP) [63-65]. In a large-scale prospective survey on ERCP carried out by the British Society of Gastroenterology, $81 \%$ of the trainees undergoing training in ERCP had participated in more than 200 gastroscopies before their first ERCP, suggesting that most had achieved competency in basic upper $\mathrm{Gl}$ endoscopy [66]. Similarly, ASGE recommends that trainees should have completed formal training in gastroscopy and colonoscopy before commencing DAE training [67]. Expertise in techniques such as hemostasis, tattooing, and polypectomy are an essential prerequisite before training in DAE $[17,28]$.

\section{RECOMMENDATION}

Trainees wishing to undertake DAE should also be trained in reading $\mathrm{SBCEs}$.

Level of agreement $94.7 \%$.

Reviewing SBCEs enables trainees to be better equipped to carry out DAEs. Depending on the findings on SBCE, trainees can assess the appropriateness of carrying out DAE, perform therapeutics when required, or obtain histology $[34,38,68]$. Trainees who fail to reach the target pathology during DAE can organize a repeat SBCE to check for the presence of pathology beyond the submucosal tattoo that marks the maximal point of insertion during DAE [17].

\section{RECOMMENDATION}

Within DAE training, trainees who wish to undertake ERCP procedures using DAE must be competent at ERCP and diagnostic DAE first.

Level of agreement $94.7 \%$.
Successful access to the biliary tree with a standard ERCP scope in Roux-en-Y altered anatomy is very challenging and often fails. A long descending small-bowel loop has to be passed through before gaining access to the bypassed duodenum. DAE can help gain access to the biliary system by providing small-bowel anchorage. Success is reported in more than $80 \%$ of cases of DAE-assisted ERCP [69]. The learning curve for ERCP is longer than that for antegrade DAE. Therefore, endoscopists who wish to be trained in DAE-assisted ERCP should have completed the training in both conventional ERCP and DAE, with completion of ERCP training being achieved before undergoing training in DAE. There is evidence that significant experience in ERCP, before training in DAE as a means to performing ERCP, can help significantly decrease the time to perform these complex procedures [70]. There is also evidence that ERCP can be combined with any DAE platform, including spiral enteroscopy [71-73].

\section{Providing training in DAE}

\section{RECOMMENDATION}

Training in DAE should be structured with a minimum of 75 DAEs, including 35 retrograde DAEs. This can either be within specialty training or undertaken as a fellowship after completion of training. The training must include regular structured hands-on experience.

Level of agreement $95.7 \%$.

There is very limited published literature on how DAE training should be delivered. The number of procedures required has not been clearly defined so far. The learning curve for antegrade DAE is thought to be easier than that for retrograde DAE, which is perceived to be more technically challenging. This is related to the difficulties encountered in achieving terminal ileal intubation and a stable position for retrograde progression with the enteroscope and overtube. There is evidence that, for antegrade DAEs, the mean duration of the procedure improves after the first 10 procedures. For retrograde DAEs, a larger number of procedures (30-35) are required to achieve an appropriate insertion depth [74-77]. Deriving evidence from training in EUS, the ASGE recommends 190 supervised EUS procedures and 50 EUS-guided fine-needle aspiration (FNA) procedures [78].

In view of the limited evidence and the expert opinion, it has therefore been suggested that a minimum of 75 procedures, including 35 retrograde DAEs, should be carried out for training purposes. It is recommended that trainees should aim to carry out a high number of DAEs during their fellowship to enrich their experience and ensure adequate exposure to varied small-bowel pathologies. DAE technique is likely to improve with independent practice, even beyond fellowship training. This is supported by evidence from training in other types of advanced endoscopy procedures, where improvement in technique continued beyond training [79].

Some endoscopy training curricula highlight the importance of quality markers rather than the number of procedures per- 
formed during a training period. In the case of ERCP, this is the ability to cannulate the bile duct in at least $90 \%$ of cases [80]. This has also been applied to training in colonoscopy, where the cecal intubation rate is considered to be an important aspect of training, independent of the number of colonoscopies performed [81]. These quality indicators are harder to define in the case of DAE, considering the variety of indications for DAE and the varied location of the pathology within the small bowel. One such quality indicator in DAE is the ability to reach the target pathology without a trainer taking over. Other quality indicators for training in DAE can be adapted from the recently described quality performance indicators in DAE, which include appropriate indication and adequate bowel preparation for DAE. The diagnostic yield reflects appropriate indication for DAE and the rate of successful therapeutic intervention should be recorded.

\section{RECOMMENDATION}

DAE training centers should have a radiology small-bowel multidisciplinary team (MDT) where small-bowel cases can be discussed or incorporated into an existing framework.

Level of agreement $89.5 \%$.

DAEs should be planned appropriately whilst taking into consideration the results of other investigations, such as dedicated small-bowel radiology. An appropriate indication for DAE is considered to be a key performance measure for DAE [17]. A few studies have reported on the diagnostic yield of SBCE, computed tomography enterography (CTE), and magnetic resonance enterography (MRE), as compared with DAE. They demonstrate that all these diagnostic modalities are complementary in the management of patients with small-bowel disorders, such as inflammatory bowel disease and small-bowel tumors [82 - 85]. An SBCE and dedicated small-bowel imaging (for example in the case of small-bowel tumors and strictures) helps to determine the best route of approach for DAE to maximize the chances of reaching the previously identified small-bowel pathology [34, 86]. Dedicated small-bowel cross-sectional imaging can also give information on the number of lesions, mural and extramural pathology, and vascularity of any lesion.

A small-bowel multidisciplinary team (MDT), including radiology, provides the right forum for discussion of these complex cases and the most appropriate management strategy for individual patients with co-morbidities. It can also be helpful to discuss patients with negative radiological investigations where the suspicion of small-bowel pathology remains high.

\section{Knowledge and maintaining competence in DAE}

\section{RECOMMENDATION}

Currently, no formal knowledge assessment is proposed for DAE. It is highly recommended that international societies develop online modules and courses on DAE, which are currently lacking across Europe.

Level of agreement $84.2 \%$.

DAE training varies across different centers. A combination of online modules, hands-on training on animal models, and live endoscopy should be developed to cover core topics and provide background knowledge on small-bowel pathologies and their management. Trainees should be introduced to common pathologies to improve their confidence in the recognition of pathologies. Less common pathologies, development of management plans, and report writing should also be covered once trainees are more proficient. In these courses, assessment, feedback, and discussion should be encouraged to improve the learning process in DAE [87].

Porcine models have been used successfully for training in gastroscopy, achievement of hemostasis in Gl bleeding, and ERCP [88-90]. They have also been used for training in DBE [91] and DBE-assisted ERCP in patients with post-surgical altered anatomy [92]. These models can provide simulated clinical scenarios for trainees prior to supervised practical endoscopic procedures in patients, which has shown improvement in the achievement of endoscopic parameters [88].

Virtual reality simulation training is another form of training that can be explored to potentially improve endoscopic performance in DAE. A recent meta-analysis on the use of virtual reality to train in gastroscopy, colonoscopy, and sigmoidoscopy has shown that it can improve the rate of independent procedure completion, the overall rating of performance, and mucosal visualization [93].

\section{RECOMMENDATION}

Within the DAE training fellowship, basic procedural aspects, equipment checks, and technique for the subtype of DAE should be covered with formal evaluation. Level of agreement $94.7 \%$.

Trainees should be knowledgeable about all available platforms for DAE, but not necessarily competent in all subtypes of DAE. They should be trained in the DAE technique that is undertaken routinely within their training center. They must be familiar with the set-up and the mechanism behind the push-and-pull technique applied during SBE (Olympus Medical Systems, Tokyo, Japan) [94] and DBE (Fujifilm Inc., Tokyo, Japan) [9], and the use of an overtube and balloons to help progression and anchorage within the small bowel [95-98]. They 
should also be familiar with manual spiral enteroscopy (Spirus Medical, LCC, West Bridgewater, Massachusetts, USA) [99] and the use of a rotating soft-plastic spiral at the tip of a dedicated enteroscope that pleats the bowel onto the instrument shaft as an alternative to balloons and overtube [99-102]. Motorized spiral enteroscopy (Olympus Medical Systems) [103,104] is currently being evaluated for its efficacy and safety, and some results have been published from a pilot clinical trial [105]. A user-controlled electric motor is embedded in the endoscope's handle to rotate a short, flexible, spiral overtube that is attached to a rotation coupler located on the endoscope's insertion tube. The principle of a rotating spiral overtube is based on that of the manual spiral enteroscope.

Trainees must be familiar with the indications for DAE, its adverse events, and the limitations and contraindications of these procedures. Trainees must also become proficient in the management of patients who require DAE while on anticoagulant medication. They must be trained in obtaining full, written informed consent for DAE procedures through thorough explanation of the indications, benefits, and potential risks. They should also be able to give patients clear instructions regarding pre-procedure bowel preparation [25]. Trainees must be aware of DAE-related complication rates and local policies on bowel preparation. Both these factors are key performance indicators in DAE [17].

Trainees must be able to appreciate the advantages of using carbon dioxide insufflation compared with air as this has been shown to demonstrate improvements in peri- and post-procedure comfort scores and reduced sedation requirements. Trainees should recognize that minimizing gaseous insufflation is beneficial to overall performance and patient comfort $[106,107]$.

Trainees should be able to identify patients who are at the highest risk during DAE. For example, patients with severe mucosal ulceration are at high risk of perforation as the overtube may cause trauma to the ulcerated mucosa.

Within Europe, there is variation in sedation practice for DAE, but deeper sedation is favored overall because of the length of the procedure $[108,109]$. The trainee is expected to be familiar with local sedation practice and be proficient in the management of sedation-related emergencies and adverse events [110].

The ESGE Quality Improvement performance measures in small-bowel endoscopy recommends auditing comfort scores for route of DAE approach, sedation, gaseous insufflation, type of DAE, and endoscopist experience [17].

\section{RECOMMENDATION}

Within DAE fellowships, the indications for DAE should ideally be covered within the cases encountered, including small-bowel bleeding, small-bowel tumors, celiac disease, Crohn's disease, polyposis syndromes, abnormal radiology, and miscellaneous cases.

Level of agreement $100 \%$.
Case volume within a DAE training center should enable trainees to cover most of the common indications for DAE. The commonest indication would be small-bowel bleeding due to vascular lesions; DAE would serve to treat the underlying cause of bleeding with APC, hemoclips, and adrenaline injection to achieve hemostasis $[38,111]$. DAE might be pursued to assess suspected Crohn's disease or to rule out celiac disease-associated complications and support this with a histological diagnosis $[68,112]$. In the case of small-bowel strictures, DAE is indicated for a histological diagnosis, endoscopic balloon dilation of the stenosis, or retrieval of a retained small-bowel capsule [113115]. Histological diagnosis of suspected small-bowel tumors is another indication for DAE [86]. A submucosal tattoo can be placed to help guide surgical resection of a tumor [36]. Patients with genetic disorders such as Peutz-Jeghers syndrome undergo regular polypectomies during DAE to avoid surgery for polyp-related complications, such as intussusception and bleeding $[116,117]$. An up-to-date logbook of procedures should be kept by trainees to reflect the indication, procedure details, and management of patients with small-bowel pathology undergoing DAE.

\section{RECOMMENDATION}

Within DAE fellowships, the contraindications for DAE should be covered within the small-bowel cases encountered and by discussion at a radiology small-bowel MDT. Level of agreement $100 \%$.

Through regular discussions at small-bowel radiology MDT meetings, trainees can be made aware of the contraindications for DAE, which include relative contraindications, such as the presence of esophageal varices and esophageal strictures, and give consideration to alternative management for these patients [118]. Trainees should also be aware of the absolute contraindications for DAE in patients with luminal perforations or recent Gl surgery and anastomosis, where trauma from the overtube and the push-and-pull technique can result in disruption of the anastomosis.

\section{RECOMMENDATION}

During DAE training, either formal or informal evaluation (depending on country) needs to be completed by the trainers for diagnostic DAE and therapeutic DAE. Level of agreement $100 \%$.

Formal or informal feedback should be provided to trainees in DAE, similar to the feedback given to trainees during basic or more advanced endoscopy training [119]. This ensures quality standards are maintained in the level of care that is provided to patients [120] and in the training that is being delivered. Evaluation should be carried out for both diagnostic and therapeutic 
procedures, depending on the degree of procedure difficulty, and should cover evaluation pre-procedure, during the procedure, and post-procedure. Trainees should be assessed on their ability to assess patient fitness for DAE and their skills at gaining consent for DAE, which includes giving an explanation of the procedure to patients. Procedure-related feedback should include quality assessment parameters, such as the ability to reach the pathological lesion, duration of examination, depth of scope insertion during DAE, mucosal assessment on withdrawal, interpretation of findings, and ability to perform therapeutic procedures and deal with potential complications during DAE $[121,122]$. Trainees should also be able to advise on postDAE care for patients. They should be able to formulate an appropriate management plan for patients who need regular DAEs, and those who need intraoperative enteroscopy or surgical resection following DAE.

In the UK, DOPS is used to assess training formally for other endoscopic procedures such as gastroscopy and colonoscopy $[123,124]$. DOPS provides assessment in three areas, namely pre-procedure, technical, and post-procedure/non-technical skills [125]. The same system is being proposed for training in DAE in the UK, enabling competency in DAE to be assessed formally. A formal or informal format analogous to DOPS could be adopted across Europe. Provision of training is also one of the key performance indicators for DAE recently proposed by the ESGE [17].

\section{RECOMMENDATION}

DAE trainees should have the opportunity to perform therapeutic DAE (in a minimum of $50 \%$ of the total number of DAEs performed) including most of the following therapeutic procedures: hemostasis techniques (adrenaline injection, hemoclip placement, and APC), retrieval of foreign bodies, stricture dilation, polypectomy, and insertion of feeding tubes.

Level of agreement $94.7 \%$.

In a training fellowship in DAE, trainees should have the opportunity to have hands-on training in therapeutic procedures under supervision in $50 \%$ of the procedures they perform. Moreover, the procedure details should be recorded by the trainee in a logbook to reflect experience during the training period. This includes the application of endotherapy for hemostasis (adrenaline injection, hemoclip placement, and APC to Dieulafoy lesions, angioectasias, or bleeding ulcers) $[111,126,127]$. Trainees should also be instructed on the retrieval of foreign bodies (mainly retained capsules) in the context of small-bowel Crohn's disease or anti-inflammatory enteropathy-related strictures $[114,128]$, and endoscopic balloon dilation of strictures $[129,130]$. Direct jejunostomy tube placement during DAE is another important aspect of training [131-133].

Trainees performing polypectomies should appreciate the risk of bleeding and perforation that is associated with the resection of large pedunculated polyps in the small bowel. These polyps are challenging because they are very often large and occupy most of the small-bowel lumen. This can make injection with adrenaline and normal saline even more challenging than endoscopic mucosal resection in the lower Gl tract. Post-polypectomy clip placement to the polyp stalk after resection is good practice and minimizes the risk of delayed complications [134].

For each therapeutic procedure, potential complications, safety measures, and how to avoid complications should be covered within the therapeutic lists.

\section{RECOMMENDATION}

Within DAE fellowships, trainees must have the ability to recognize and deal with the complications of DAE and their prevention.

Level of agreement $100 \%$.

There is no reported difference in complication rates according to the different DAE platforms $[99,135,136]$. The rates of complications should be less than $1 \%$ for diagnostic DAE and less than $5 \%$ for therapeutic DAE [17].

Trainees must minimize and recognize overtube mucosal trauma by carefully inspecting the mucosa for any obvious tears on withdrawal and treat any partial thickness tears with endoclips as appropriate [137]. Minimizing procedure time can help reduce the risk of pancreatitis $[52,138]$. Aspiration pneumonia is another complication that can be associated with DAE [139]. Trainees should recognize patients who are at increased risk of aspiration pneumonia and encourage the application of intermittent suctioning during the procedure.

Trainees should also recognize that complication rates for therapeutic DAE are higher and take measures to minimize complications. Polypectomy-related perforation and bleeding may be reduced by adequate injection of the base/stalk of the polyp with saline and adrenaline and by the application of endoclips to minimize delayed complications [25,41,134]. Limiting stricture dilation to short non-inflammatory strictures can minimize the risk of perforation [140]. Bleeding can also occur secondary to partially treated bleeding lesions such as arteriovenous malformations. ESGE recommends pre-injection of the submucosa with saline before application of APC for larger lesions [25].

Situational awareness and early recognition of adverse events are essential for trainees especially prior to performing therapeutic procedures. Trainees should pre-empt potential complications that may arise and be prepared to manage them rapidly. This implies that they should be aware of the potential difficulty that can be encountered during introduction of accessory equipment through the enteroscope channel due to small-bowel looping. 


\section{RECOMMENDATION}

Within DAE fellowships, trainees must acquire skills to be able to independently advise on/manage small-bowel pathology post DAE, ongoing bleeding, or the need for other interventions.

Level of agreement $100 \%$.

Trainees are encouraged to regularly attend and participate in small-bowel MDTs. This will help them acquire knowledge and confidence to manage patients with small-bowel pathologies. Dedicated small-bowel imaging or a repeat SBCE may be required in patients with suspected small-bowel bleeding where the pathology has not been identified on the first SBCE and DAE [36]. Patients with angioectasias will need regular monitoring of their hemoglobin level. The management of such patients may include repeat DAE with APC, in conjunction with iron therapy and pharmacotherapy, such as somatostatin analogues in those who have refractory anemia $[127,141$, 142]. Patients with small-bowel tumors without metastatic disease should be considered for surgery after discussion at appropriate MDTs $[86,143]$. Patients with small-bowel strictures might need repeated endoscopic balloon dilation or surgery, depending on their response to endoscopic balloon dilation and the number of strictures they have $[144,145]$.

\section{RECOMMENDATION}

International societies are encouraged to set up DAE courses for trainees to attend (no regular set up at present) and to set up a formal or informal "buddying-up" or mentoring system for DAE units to offer training to other gastroenterologists in their country.

Level of agreement $89.5 \%$.

There is no published evidence on the impact of DAE courses on training. However, DAE courses led by expert trainers can prove to be of good educational value to trainees in the initial stages of DAE training. These can be based on lectures that cover the basic principles of DAE, model-based learning, and live DAE [91]. Currently, these courses are lacking but, once set up, they may play an important role in DAE training.

Some endoscopy units do not have a high volume of enteroscopy cases resulting in a less than ideal environment for training purposes. A "buddying-up" or mentoring system among centers is therefore encouraged to give the opportunity to trainees from low-volume centers to train in DAE at other higher volume centers. This will ensure that DAE trainees are exposed to an adequate number of DAE procedures and related endotherapy, in order to enable them to achieve independence by the end of their training period.

- Fig. 2 summarizes training in DAE.

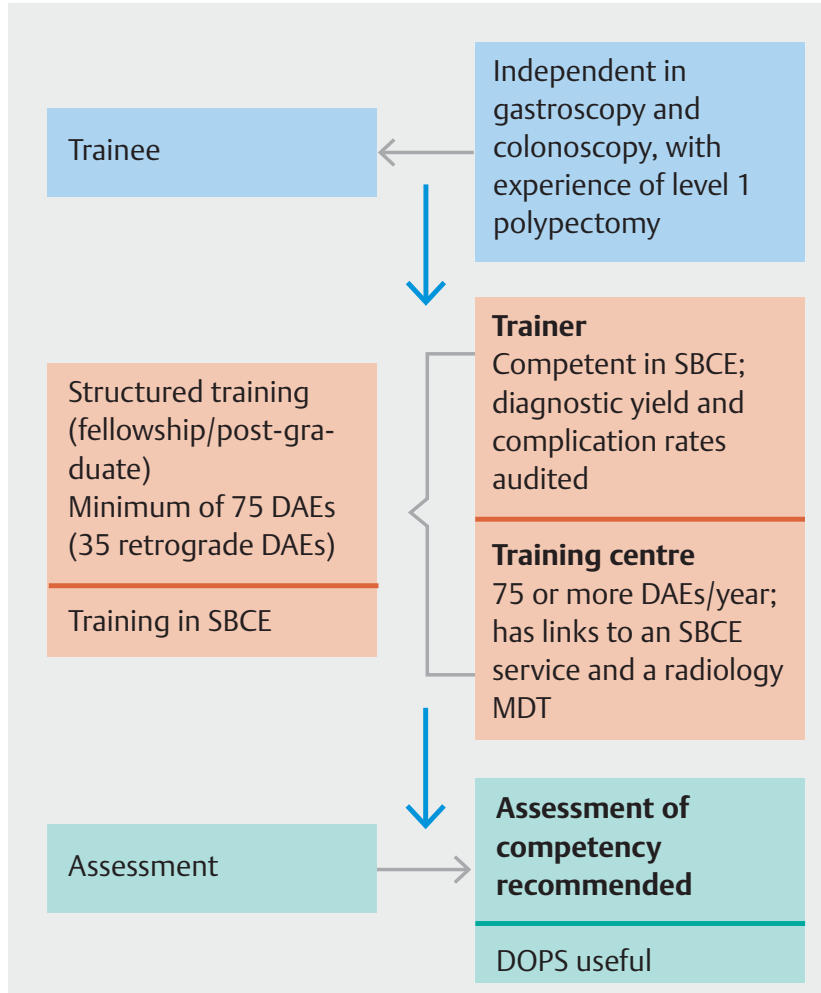

- Fig. 2 Diagram summarizing the ESGE training curriculum for device-assisted enteroscopy (DAE).

SBCE, small-bowel capsule endoscopy; DOPS, Direct Observation of Procedural Skills.

\section{Conclusions}

This document by the ESGE small-bowel Curricula Working Group is the first attempt of its kind aiming to provide a framework and criteria for training in small-bowel endoscopy, covering both SBCE and DAE. In view of the lack of published evidence, most of these criteria are based on expert opinion through consensus among a team of experts, who have also drawn upon the recently published Performance Measures for small-bowel endoscopy, part of the ESGE Quality Improvement Initiative [17], and the ESGE clinical and technical guidelines on small-bowel endoscopy $[5,25]$.

Dual competency in both SBCE and DAE is of utmost importance and can help to enhance training in small-bowel endoscopy. Training in DAE can require a long duration and is similar to that of other complex endoscopy procedures, such as ERCP and EUS.Access to a small-bowel radiology MDT is essential while training in small-bowel endoscopy and ensures the development of knowledge for thorough management of patients with small-bowel disorders.

It is envisaged that, over the next few years, through the support of the ESGE, and regional and national societies, formal training courses in small-bowel endoscopy (particularly in DAE) will be developed, in order to allow wider dissemination of practical knowledge concerning high quality performance of small-bowel endoscopy internationally. However, while this 
happens, the clinical practice of small-bowel endoscopy continues to evolve towards another futuristic era. The introduction of new technologies, such as the application of artificial intelligence for the impressive enhancement of accuracy, diagnostic yield, and speed of SBCE reading, are very likely to influence clinical practice and delivery of training concerning this device $[146,147]$.

Our ESGE guidelines, performance measures, and curriculum will continue to be updated to reflect these exciting developments and any influence they may have on current practice.

\section{Disclaimer}

ESGE Position Statements represent a consensus of best practice based on the available evidence at the time of preparation. This is NOT a guideline but a proposal for training in small-bowel endoscopy. The statements may not apply in all situations and should be interpreted in the light of specific clinical situations and resource availability. Further controlled clinical studies may be needed to clarify aspects of these statements, and revision may be necessary as new data appear. Clinical considerations may justify a course of action at variance with these recommendations.

This ESGE Position Statement is intended to be an educational device to provide information that may assist endoscopists in providing care to patients. They are not rules and should not be construed as establishing a legal standard of care or as encouraging, advocating, requiring, or discouraging any particular treatment.

The legal disclaimer for ESGE guidelines applies to the present position statement [148].

\section{Acknowledgments}

The authors gratefully acknowledge the contributions from the following: Dr. Stuart Gittens, of ECD Solutions, for the development and running of the web platform; Cathy Bennett of Office of Research and Innovation, Royal College of Surgeons in Ireland Coláiste Ríoga na Máinleá in Éirinn, Dublin, Ireland; Iwona Escreet and all at Hamilton Services for project administrative support.

The authors would like to thank the experts in the field of smallbowel endoscopy who participated in the voting rounds that led to the development of this guideline: Anastasios Koulaouzidis, Simon Panter, Hanneke Beaumont, Emanuele Rondonotti, Konstantinos Triantafyllou, Enrique Perez-Cuadrado-Robles, Salvatore Oliva, Deirdre McNamara, Bruno Rosa, Pierre Ellul, Cristiano Spada, Wojciech M. Marlicz, Gabriel Rahmi, and Abraham Eliakim.

R. Bisschops is supported by the Research Foundation-Flanders (FWO). J.E. East was funded by the National Institute for Health Research (NIHR) Oxford Biomedical Research Centre. The views expressed are those of the author(s) and not necessarily those of the National Health Service, the NIHR, or the Department of Health.
Competing interests

M. Arvanitakis has received lecture fees from Olympus (2019-2020). P. Baltes has received speaker's fees from Medtronic (2014 to present). R. Bisschops has received research support, speaker's and consultancy fees from Medtronic, Cook, Pentax, and Fujifilm (20092020), he has also received consultancy and speaker's fees from Norgine, Gl supply, Medivators, and Boston Scientific (2009-2020). C. Carretero has received speaker's and consultancy fees from Medtronic (ongoing). E. Dekker has received speaker's fees from Olympus (2018), Roche (2016, 2018), and GI Supply (2019), has provided consultancy to Fujifilm (2017), Olympus (2019), Tillots (2018), GI Supply (2018 to present), and CPP-FAP (2019); she has received equipment on loan from Fujifilm (2017 to present); she received a research grant from Fujifilm. E.J. Despott has received speaker's honoraria from Fujifilm and Aquilant Endoscopy (2017 to present), and educational grants from Fujifilm, Aquilant Endoscopy, Pentax Medical, and Olympus Medical (2017 to present). M. Dinis-Ribeiro is co-editor in-chief of Endoscopy. X. Dray is a co-founder and shareholder of Augmented Endoscopy (2019 to present), and has given training for Fujifilm and Medtronic (2010 - 2019); he also holds a patent related to the guideline: European patent EP18305275. J.E. East is on the clinical advisory boards of Boston Scientific, Lumendi (2017-2019) and Satisfai Health (2020). G. Johnson has received speaker's fees from Boston Scientific (2012 to present) and has been a faculty member for annual training courses supported by Olympus, Pentax, and Boston Scientific (2012 to present). M. Keuchel has received speaker's fees from Medtronic and Olympus (2015 to present); he is co-editor of the book Video Capsule Endoscopy published by Springer. A. Murino has acted as a consultant for Boston Scientific and GI supply (2019), he has received academic grants from Fujifilm, Aquilant Endoscopy, Norgine, and Olympus $(2017-2020)$. T. Ponchon has received research support from Olympus (2020). S. Chetcuti Zammit, P. Pimentel-Nunes, D. S. Sanders, and R. Sidhu declare that they have no conflict of interest.

References

[1] Bisschops R, Dekker E, East JE et al. European Society of Gastrointestinal Endoscopy (ESGE) curricula development for postgraduate training in advanced endoscopic procedures: rationale and methodology. Endoscopy 2019; 51: 976-979

[2] Hijaz NM, Septer SS, Attard TM. Present standard in pediatric gastroenterology fellowship training in the interpretation of capsule endoscopy. J Pediatr Gastroenterol Nutr 2015; 61: 421-423

[3] Read AJ, Rice MD, Conjeevaram HS et al. A deeper look at the small bowel: training pathways in video capsule endoscopy and deviceassisted enteroscopy. Dig Dis Sci 2018; 63: 2210-2219

[4] Sidhu R, Sakellariou P, McAlindon ME et al. Is formal training necessary for capsule endoscopy? The largest gastroenterology trainee study with controls. Dig Liver Dis 2008; 40: 298-302

[5] Pennazio M, Spada C, Eliakim R et al. Small-bowel capsule endoscopy and device-assisted enteroscopy for diagnosis and treatment of small-bowel disorders: European Society of Gastrointestinal Endoscopy (ESGE) Clinical Guideline. Endoscopy 2015; 47: 352-376

[6] McAlindon ME, Parker CE, Hendy P et al. Provision of service and training for small bowel endoscopy in the UK. Frontline Gastroenterol 2012; 3: 98-103

[7] Postgate A, Haycock A, Fitzpatrick A et al. How should we train capsule endoscopy? A pilot study of performance changes during a structured capsule endoscopy training program. Dig Dis Sci 2009; 54: 1672-1679

[8] Rajan E, Iyer PG, Oxentenko AS et al. Training in small-bowel capsule endoscopy: assessing and defining competency. Gastrointest Endosc 2013; 78: 617-622 
[9] Yamamoto H, Sekine $\mathrm{Y}$, Sato $\mathrm{Y}$ et al. Total enteroscopy with a nonsurgical steerable double-balloon method. Gastrointest Endosc 2001; 53: 216-220

[10] Riccioni ME, Urgesi R, Cianci R et al. Single-balloon push-and-pull enteroscopy system: does it work? A single-center, 3-year experience. Surg Endosc 2011; 25: 3050-3056

[11] Buscaglia JM, Dunbar KB, Okolo PI et al. The spiral enteroscopy training initiative: results of a prospective study evaluating the Discovery SB overtube device during small bowel enteroscopy (with video). Endoscopy 2009; 41: 194-199

[12] Rutter MD, Senore C, Bisschops R et al. The European Society of Gastrointestinal Endoscopy Quality Improvement Initiative: developing performance measures. United European Gastroenterol J 2016; 4: 30-41

[13] Albert JG, Humbla O, McAlindon ME et al. A simple evaluation tool (ET-CET) indicates increase of diagnostic skills from small bowel capsule endoscopy training courses: a prospective observational European multicenter study. Medicine (Baltimore) 2015; 94: e1941

[14] Postgate A, Tekkis P, Fitzpatrick A et al. The impact of experience on polyp detection and sizing accuracy at capsule endoscopy: implications for training from an animal model study. Endoscopy 2008; 40: 496-501

[15] Alakkari A, El-Sherif O, Dobson $\mathrm{M}$ et al. Is focused training adequate or is prior endoscopy experience needed for reliable capsule endoscopy reporting? J Gastroenterol Hepatol Res 2013; 2: 628-631

[16] Graepler F, Wolter M, Vonthein R et al. Accuracy of the size estimation in wireless capsule endoscopy: calibrating the M2A PillCam (with video). Gastrointest Endosc 2008; 67: 924-931

[17] Spada C, McNamara D, Despott EJ et al. Performance measures for small-bowel endoscopy: a European Society of Gastrointestinal Endoscopy (ESGE) Quality Improvement Initiative. Endoscopy 2019; 51: $574-598$

[18] The Joint Advisory Group on GI Endoscopy. Formative video capsule endoscopy - Patency capsule DOPS. 2016: Available from (accessed: 29 April 2020): https://www.thejag.org.uk/AboutUs/DownloadCentre.aspx

[19] Fernandez-Urien I, Panter S, Carretero C et al. International core curriculum for capsule endoscopy training courses. Endosc Int Open 2017; 5: E526-E538

[20] Korman LY, Delvaux M, Gay G et al. Capsule endoscopy structured terminology (CEST): proposal of a standardized and structured terminology for reporting capsule endoscopy procedures. Endoscopy 2005; 37: 951-959

[21] Jang BI, Lee SH, Moon JS et al. Inter-observer agreement on the interpretation of capsule endoscopy findings based on capsule endoscopy structured terminology: a multicenter study by the Korean Gut Image Study Group. Scand J Gastroenterol 2010; 45: 370 374

[22] Petroniene R, Dubcenco E, Baker JP et al. Given capsule endoscopy in celiac disease: evaluation of diagnostic accuracy and interobserver agreement. Am J Gastroenterol 2005; 100: 685-694

[23] Zheng Y, Hawkins L, Wolff J et al. Detection of lesions during capsule endoscopy: physician performance is disappointing. Am J Gastroenterol 2012; 107: 554-560

[24] Yung DE, Fernandez-Urien I, Douglas S et al. Systematic review and meta-analysis of the performance of nurses in small bowel capsule endoscopy reading. United European Gastroenterol J 2017; 5: 1061 1072

[25] Rondonotti E, Spada C, Adler S et al. Small-bowel capsule endoscopy and device-assisted enteroscopy for diagnosis and treatment of small-bowel disorders: European Society of Gastrointestinal Endoscopy (ESGE) Technical Review. Endoscopy 2018; 50: 423-446
[26] Jirapinyo P, Imaeda AB, Thompson CC. Endoscopic training in gastroenterology fellowship: adherence to core curriculum guidelines. Surg Endosc 2015; 29: 3570-3578

[27] Rajan EA, Pais SA, Degregorio BT et al. ASGE Training Committee Small-bowel endoscopy core curriculum. Gastrointest Endosc 2013; 77: $1-6$

[28] elntegrity Healthcare. 2014: Available from (accessed: 13 May 2020): https://www.eintegrity.org

[29] Lim Y], Joo YS, Jung DY et al. Learning curve of capsule endoscopy. Clin Endosc 2013; 46: 633-636

[30] Rajan E, Martinez M, Gorospe E et al. Prospective multicenter study to evaluate capsule endoscopy competency using a validated assessment tool. Gastrointest Endosc 2020; 91: 1140-1145

[31] The European Section and Board of Gastroenterology and Hepatology. Speciality Training Programme and Curriculum for Gastroenterology and Hepatology. The Blue Book; 2017: Available from (accessed: 29 April 2020): http://www.euboghorg/blue-book/

[32] Kassenärztliche Bundesvereinigung - Vereinbarung von Qualitätssicherungsmaßnahmen nach § 135 Abs. 2 SGB V für die DünndarmKapselendoskopie zur Abklärung obskurer gastrointestinaler Blutungen (Qualitätssicherungsvereinbarung Dünndarm-Kapselendoskopie). 2014: Available from (accessed: 13 May 2020): https://www. kbv.de/media/sp/Duenndarm_Kapselendoskopie.pdf

[33] Postgate A, Haycock A, Thomas-Gibson S et al. Computer-aided learning in capsule endoscopy leads to improvement in lesion recognition ability. Gastrointest Endosc 2009; 70: 310-316

[34] Gay G, Delvaux M, Fassler I. Outcome of capsule endoscopy in determining indication and route for push-and-pull enteroscopy. Endoscopy 2006; 38: 49-58

[35] Li X, Chen H, Dai J et al. Predictive role of capsule endoscopy on the insertion route of double-balloon enteroscopy. Endoscopy 2009; 41 762-766

[36] Römmele C, Ebigbo A, Schrempf M et al. Detection rate and clinical relevance of ink tattooing during balloon-assisted enteroscopy. Gastroenterol Res Pract 2017; 2017: 4969814

[37] Pasha SF, Leighton JA, Das A et al. Double-balloon enteroscopy and capsule endoscopy have comparable diagnostic yield in small-bowe disease: a meta-analysis. Clin Gastroenterol Hepatol 2008; 6: 671676

[38] Teshima CW, Kuipers EJ, van Zanten SV et al. Double balloon enteroscopy and capsule endoscopy for obscure gastrointestinal bleeding: an updated meta-analysis. J Gastroenterol Hepatol 2011; 26: 796-801

[39] Mensink PB, Haringsma J, Kucharzik T et al. Complications of double balloon enteroscopy: a multicenter survey. Endoscopy 2007; 39: 613-615

[40] Gerson LB, Tokar J, Chiorean M et al. Complications associated with double balloon enteroscopy at nine US centers. Clin Gastroenterol Hepatol 2009; 7: 1177-1182, 1182.e1171-e1173

[41] Möschler O, May A, Müller MK et al. Complications in and performance of double-balloon enteroscopy (DBE): results from a large prospective DBE database in Germany. Endoscopy 2011; 43: 484-489

[42] Despott EJ, Murino A, Hughes S et al. Mo1583 Second report of the UK multicenter DBE registry: furthering the international DBE experience. Gastrointest Endosc 2011; 73: AB394

[43] Rondonotti E, Sunada K, Yano T et al. Double-balloon endoscopy in clinical practice: where are we now? Dig Endosc 2012; 24: 209-219

[44] Moeschler O, Mueller MK. Deep enteroscopy - indications, diagnostic yield and complications. World J Gastroenterol 2015; 21: 13851393 
[45] Cotton PB, Eisen GM, Aabakken L et al. A lexicon for endoscopic adverse events: report of an ASGE workshop. Gastrointest Endosc 2010; 71: 446-454

[46] Hirai F, Beppu T, Sou S et al. Endoscopic balloon dilatation using double-balloon endoscopy is a useful and safe treatment for small intestinal strictures in Crohn's disease. Dig Endosc 2010; 22: 200204

[47] Xin L, Liao Z, Jiang YP et al. Indications, detectability, positive findings, total enteroscopy, and complications of diagnostic doubleballoon endoscopy: a systematic review of data over the first decade of use. Gastrointest Endosc 2011; 74: 563-570

[48] Möschler O, May AD, Müller MK et al. Complications in double-balloon-enteroscopy: results of the German DBE register. Z Gastroenterol 2008; 46: 266-270

[49] Yamamoto H, Yano T, Ohmiya N et al. Double-balloon endoscopy is safe and effective for the diagnosis and treatment of small-bowel disorders: prospective multicenter study carried out by expert and non-expert endoscopists in Japan. Dig Endosc 2015; 27: 331-337

[50] Lipka S, Rabbanifard R, Kumar A et al. Single versus double balloon enteroscopy for small bowel diagnostics: a systematic review and meta-analysis. J Clin Gastroenterol 2015; 49: 177-184

[51] Lenz P, Roggel M, Domagk D. Double- vs. single-balloon enteroscopy: single center experience with emphasis on procedural performance. Int J Colorectal Dis 2013; 28: 1239-1246

[52] Zepeda-Gómez S, Barreto-Zuñiga R, Ponce-de-León S et al. Risk of hyperamylasemia and acute pancreatitis after double-balloon enteroscopy: a prospective study. Endoscopy 2011; 43: 766-770

[53] Tsujikawa T, Bamba S, Inatomi $O$ et al. Factors affecting pancreatic hyperamylasemia in patients undergoing peroral single-balloon enteroscopy. Dig Endosc 2015; 27: 674-678

[54] Kopacova M, Tacheci I, Rejchrt S et al. Double balloon enteroscopy and acute pancreatitis. World J Gastroenterol 2010; 16: 2331-2340

[55] Pata C, Akyüz U, Erzin Y et al. Post-procedure elevated amylase and lipase levels after double-balloon enteroscopy: relations with the double-balloon technique. Dig Dis Sci 2010; 55: 1982-1988

[56] Nakayama S, Tominaga K, Obayashi T et al. The prevalence of adverse events associated with double-balloon enteroscopy from a single-centre dataset in Japan. Dig Liver Dis 2014; 46: 706-709

[57] Rabeneck L, Paszat LF, Hilsden RJ et al. Bleeding and perforation after outpatient colonoscopy and their risk factors in usual clinical practice. Gastroenterology 2008; 135: 1899-1906, 1906.e1891

[58] Chukmaitov A, Bradley C], Dahman B et al. Association of polypectomy techniques, endoscopist volume, and facility type with colonoscopy complications. Gastrointest Endosc 2013; 77: 436-446

[59] Singh H, Penfold RB, De Coster C et al. Predictors of serious complications associated with lower gastrointestinal endoscopy in a major city-wide health region. Can J Gastroenterol 2010; 24: 425-430

[60] Lorenzo-Zúñiga V, Moreno de Vega V, Doménech E et al. Endoscopist experience as a risk factor for colonoscopic complications. Colorectal Dis 2010; 12: e273-e277

[61] Saito Y, Uraoka T, Yamaguchi Y et al. A prospective, multicenter study of 1111 colorectal endoscopic submucosal dissections (with video). Gastrointest Endosc 2010; 72: 1217-1225

[62] Kim J. Training in Endoscopy: Enteroscopy. Clin Endosc 2017; 50: 328-333

[63] DiMaio C], Mishra G, McHenry L et al. EUS core curriculum. Gastrointest Endosc 2012; 76: 476-481

[64] Jorgensen J, Kubiliun N, Law JK et al. Endoscopic retrograde cholangiopancreatography (ERCP): core curriculum. Gastrointest Endosc 2016; 83: 279-289
[65] Van Dam J, Brady PG, Freeman M et al. Guidelines for training in electronic ultrasound: guidelines for clinical application. From the ASGE. American Society for Gastrointestinal Endoscopy. Gastrointest Endosc 1999; 49: 829-833

[66] Williams E], Taylor S, Fairclough P et al. Are we meeting the standards set for endoscopy? Results of a large-scale prospective survey of endoscopic retrograde cholangio-pancreatograph practice. Gut 2007; 56: 821-829

[67] Pohl J, Blancas JM, Cave D et al. Consensus report of the 2nd International Conference on double balloon endoscopy. Endoscopy 2008; 40: $156-160$

[68] Tun GS, Rattehalli D, Sanders DS et al. Clinical utility of double-balloon enteroscopy in suspected Crohn's disease: a single-centre experience. Eur J Gastroenterol Hepatol 2016; 28: 820-825

[69] Keren D, Madi H, Matter I et al. Feasibility and importance of enteroscopy after gastric bypass. Obes Surg 2017; 27: 1309-1315

[70] Kashani A, Abboud G, Lo SK et al. Double balloon enteroscopy-assisted endoscopic retrograde cholangiopancreatography in Rouxen-Y gastric bypass anatomy: expert vs. novice experience. Endosc Int Open 2018; 6: E885-E891

[71] Ali MF, Modayil R, Gurram KC et al. Spiral enteroscopy-assisted ERCP in bariatric-length Roux-en-Y anatomy: a large single-center series and review of the literature (with video). Gastrointest Endosc 2018; 87: $1241-1247$

[72] Shao XD, Qi XS, Guo XZ. Endoscopic retrograde cholangiopancreatography with double balloon enteroscope in patients with altered gastrointestinal anatomy: A meta-analysis. Saudi J Gastroenterol 2017; 23: 150-160

[73] Yane K, Katanuma A, Maguchi $\mathrm{H}$ et al. Short-type single-balloon enteroscope-assisted ERCP in postsurgical altered anatomy: potential factors affecting procedural failure. Endoscopy 2017; 49: 69-74

[74] Mehdizadeh S, Ross A, Gerson L et al. What is the learning curve associated with double-balloon enteroscopy? Technical details and early experience in 6 U.S. tertiary care centers. Gastrointest Endosc 2006; 64: 740-750

[75] Mehdizadeh S, Han N], Cheng DW et al. Success rate of retrograde double-balloon enteroscopy. Gastrointest Endosc 2007; 65: 633639

[76] Tee HP, How SH, Kaffes AJ. Learning curve for double-balloon enteroscopy: Findings from an analysis of 282 procedures. World J Gastrointest Endosc 2012; 4: 368-372

[77] James PD, Antonova L, Martel $\mathrm{M}$ et al. Measures of trainee performance in advanced endoscopy: A systematic review. Best Pract Res Clin Gastroenterol 2016; 30: 421-452

[78] Eisen GM, Dominitz JA, Faigel DO et al. Guidelines for credentialing and granting privileges for endoscopic ultrasound. Gastrointest Endosc 2001; 54: 811-814

[79] Biau DJ, Williams SM, Schlup MM et al. Quantitative and individualized assessment of the learning curve using LC-CUSUM. Br J Surg 2008; 95: 925-929

[80] Domagk D, Oppong KW, Aabakken L et al. Performance measures for endoscopic retrograde cholangiopancreatography and endoscopic ultrasound: A European Society of Gastrointestinal Endoscopy (ESGE) Quality Improvement Initiative. United European Gastroenterol J 2018; 6: 1448-1460

[81] Marshall JB. Technical proficiency of trainees performing colonoscopy: a learning curve. Gastrointest Endosc 1995; 42: 287-291

[82] Rondonotti E, Koulaouzidis A, Georgiou J et al. Small bowel tumours: update in diagnosis and management. Curr Opin Gastroenterol 2018; 34: 159-164 
[83] Dionisio PM, Gurudu SR, Leighton JA et al. Capsule endoscopy has a significantly higher diagnostic yield in patients with suspected and established small-bowel Crohn's disease: a meta-analysis. Am J Gastroenterol 2010; 105: 1240-1248; quiz 1249

[84] Kopylov U, Yung DE, Engel T et al. Diagnostic yield of capsule endoscopy versus magnetic resonance enterography and small bowel contrast ultrasound in the evaluation of small bowel Crohn's disease: Systematic review and meta-analysis. Dig Liver Dis 2017; 49: 854-863

[85] Ethun CG, Postlewait LM, Baptiste GG et al. Small bowel neuroendocrine tumors: A critical analysis of diagnostic work-up and operative approach. J Surg Oncol 2016; 114: 671-676

[86] Manguso N, Gangi A, Johnson J et al. The role of pre-operative imaging and double balloon enteroscopy in the surgical management of small bowel neuroendocrine tumors: Is it necessary? J Surg Oncol 2018; 117: 207-212

[87] Axe K, Hawkes E, Turner J et al. PWE-433 A qualitative assessment of cognitive framework development in novice endoscopists: implications for programmed lesion recognition training. Gut 2015; 64: (Suppl. 01): A400

[88] Neumann M, Hahn C, Horbach T et al. Score card endoscopy: a multicenter study to evaluate learning curves in 1-week courses using the Erlangen Endo-Trainer. Endoscopy 2003; 35: 515-520

[89] Fisher L, Ormonde DG, Riley RH et al. Endoscopic skills training in a simulated clinical setting. Simul Healthc 2010; 5: 232-237

[90] Hochberger J, Euler K, Naegel A et al. The compact Erlangen Active Simulator for Interventional Endoscopy: a prospective comparison in structured team-training courses on "endoscopic hemostasis" for doctors and nurses to the "Endo-Trainer" model. Scand J Gastroenterol 2004; 39: 895-902

[91] May A, Nachbar L, Schneider M et al. Push-and-pull enteroscopy using the double-balloon technique: method of assessing depth of insertion and training of the enteroscopy technique using the Erlangen Endo-Trainer. Endoscopy 2005; 37: 66-70

[92] Maiss ], Diebel H, Naegel A et al. A novel model for training in ERCP with double-balloon enteroscopy after abdominal surgery. Endoscopy 2007; 39: 1072-1075

[93] Khan R, Plahouras ], Johnston BC et al. Virtual reality simulation training in endoscopy: a Cochrane review and meta-analysis. Endoscopy 2019; 51: 653-664

[94] Hartmann D, Eickhoff A, Tamm R et al. Balloon-assisted enteroscopy using a single-balloon technique. Endoscopy 2007; 39: (Suppl. 01): E276

[95] Moran RA, Barola S, Law JK et al. A randomized controlled trial comparing the depth of maximal insertion between anterograde singleballoon versus spiral enteroscopy. Clin Med Insights Gastroenterol 2018; 11: 1179552218754881

[96] García-Correa JJE, Ramírez-García JJ, García-Contreras LF et al. Double-balloon enteroscopy: Indications, approaches, diagnostic and therapeutic yield, and safety. Early experience at a single center. Rev Gastroenterol Mex 2018; 83: 31-40

[97] Lu Z, Qi Y, Weng J et al. Efficacy and safety of single-balloon versus double-balloon enteroscopy: a single-center retrospective analysis. Med Sci Monit 2017; 23: 1933-1939

[98] Holleran G, Valerii G, Tortora A et al. The use of single balloon enteroscopy in Crohn's disease and its impact on clinical outcome. Scand J Gastroenterol 2018; 53: 925-929

[99] Khashab MA, Lennon AM, Dunbar KB et al. A comparative evaluation of single-balloon enteroscopy and spiral enteroscopy for patients with mid-gut disorders. Gastrointest Endosc 2010; 72: 766-772

[100] Schneider M, Höllerich J, Beyna T. Device-assisted enteroscopy: A review of available techniques and upcoming new technologies. World J Gastroenterol 2019; 25: 3538-3545
[101] Despott E], Murino A, Bourikas L et al. A prospective comparison of performance during back-to-back, anterograde manual spiral enteroscopy and double-balloon enteroscopy. Dig Liver Dis 2015; 47: 395-400

[102] May A, Manner H, Aschmoneit I et al. Prospective, cross-over, singlecenter trial comparing oral double-balloon enteroscopy and oral spiral enteroscopy in patients with suspected small-bowel vascular malformations. Endoscopy 2011; 43: 477-483

[103] Neuhaus H, Beyna T, Schneider M et al. Novel motorized spiral enteroscopy: first clinical case. VideoGIE 2016; 1: 32-33

[104] Mans L, Arvanitakis M, Neuhaus $\mathrm{H}$ et al. Motorized spiral enteroscopy for occult bleeding. Dig Dis 2018; 36: 325-327

[105] Beyna T, Arvanitakis M, Schneider M et al. Motorised spiral enteroscopy: first prospective clinical feasibility study. Gut 2020: doi:10.1136/gutjnl-2019-319908

[106] Aquino JCM, Bernardo WM, de Moura DTH et al. Carbon dioxide versus air insufflation enteroscopy: a systematic review and meta-analysis based on randomized controlled trials. Endosc Int Open 2018; 6: E637-E645

[107] Shiani A, Lipka S, Lai A et al. Carbon dioxide versus room air insufflation during balloon-assisted enteroscopy: A systematic review with meta-analysis. Endosc Int Open 2017; 5: E67-E75

[108] Ching HL, Branchi F, Sanders DS et al. Paradigm shift: should the elderly undergo propofol sedation for DBE? A prospective cohort study Frontline Gastroenterol 2018; 9: 192-199

[109] Jensen JT, Hornslet P, Konge L et al. High efficacy with deep nurseadministered propofol sedation for advanced gastroenterologic endoscopic procedures. Endosc Int Open 2016; 4: E107-E111

[110] Sidhu R, Turnball D, Newton M et al. Deep sedation and anaesthesia in complex gastrointestinal endoscopy: a joint position statement endorsed by the British Society of Gastroenterology (BSG), Joint Advisory Group (JAG) and Royal College of Anaesthetists (RCOA). Frontline Gastroenterol 2019; 10: 141-147

[111] Rodrigues JP, Pinho R, Rodrigues A et al. Diagnostic and therapeutic yields of urgent balloon-assisted enteroscopy in overt obscure gastrointestinal bleeding. Eur J Gastroenterol Hepatol 2018; 30: 13041308

[112] Tomba C, Sidhu R, Sanders DS et al. Celiac disease and double-balloon enteroscopy: what can we achieve? The experience of 2 European tertiary referral centers. J Clin Gastroenterol 2016; 50: 313317

[113] Baars JE, Theyventhiran R, Aepli P et al. Double-balloon enteroscopyassisted dilatation avoids surgery for small bowel strictures: A systematic review. World J Gastroenterol 2017; 23: 8073-8081

[114] Makipour K, Modiri AN, Ehrlich A et al. Double balloon enteroscopy: effective and minimally invasive method for removal of retained video capsules. Dig Endosc 2014; 26: 646-649

[115] Mitsui K, Fujimori S, Tanaka S et al. Retrieval of retained capsule endoscopy at small bowel stricture by double-balloon endoscopy significantly decreases surgical treatment. J Clin Gastroenterol 2016; 50: 141-146

[116] Belsha D, Urs A, Attard T et al. Effectiveness of double-balloon enteroscopy-facilitated polypectomy in pediatric patients with PeutzJeghers syndrome. J Pediatr Gastroenterol Nutr 2017; 65: 500-502

[117] Goverde A, Korsse SE, Wagner A et al. Small-bowel surveillance in patients with Peutz-Jeghers syndrome: comparing magnetic resonance enteroclysis and double balloon enteroscopy. J Clin Gastroenterol 2017; 51: e27-e33

[118] Buscaglia JM, Okolo PI. Deep enteroscopy: training, indications, and the endoscopic technique. Gastrointest Endosc 2011; 73: 10231028

[119] Barton JR, Corbett S, van der Vleuten CP et al. The validity and reliability of a Direct Observation of Procedural Skills assessment tool: 
assessing colonoscopic skills of senior endoscopists. Gastrointest Endosc 2012; 75: 591-597

[120] Rees C], Thomas Gibson S, Rutter MD et al. UK key performance indicators and quality assurance standards for colonoscopy. Gut 2016; 65: $1923-1929$

[121] American Society for Gastrointestinal Endoscopy. Position statement. Maintaining competency in endoscopic skills. Gastrointest Endosc 1995; 42: 620-621

[122] Morgan D, Upchurch B, Draganov P et al. Spiral enteroscopy: prospective U.S. multicenter study in patients with small-bowel disorders. Gastrointest Endosc 2010; 72: 992-998

[123] Siau K, Crossley J, Dunckley P et al. Direct observation of procedural skills (DOPS) assessment in diagnostic gastroscopy: nationwide evidence of validity and competency development during training. Surg Endosc 2020; 34: 105-114

[124] Siau K, Dunckley P, Valori R et al. Changes in scoring of Direct Observation of Procedural Skills (DOPS) forms and the impact on competence assessment. Endoscopy 2018; 50: 770-778

[125] The Joint Advisory Group on GI Endoscopy. Formative DOPS: Endoscopic retrograde cholangiopancreatography (ERCP). 2016: Available from (accessed: 29 April 2020): https://www.thejag.org.uk/ AboutUs/DownloadCentre.aspx

[126] Arribas Anta J, Zaera de la Fuente C, Martín Mateos R et al. Evaluation of the efficacy of therapeutic endoscopy in gastrointestinal bleeding secondary to angiodysplasias. Rev Gastroenterol Mex 2017; 82: 2631

[127] Fan GW, Chen TH, Lin WP et al. Angiodysplasia and bleeding in the small intestine treated by balloon-assisted enteroscopy. J Dig Dis 2013; 14: 113-116

[128] Chen WC, Bartel M, Kroner T et al. Double balloon enteroscopy is a safe and effective procedure in removing entrapped foreign objects in the small bowel for up to 3 months. J Laparoendosc Adv Surg Tech A 2015; 25: 392-395

[129] Kanamori A, Sugaya T, Tominaga K et al. Endoscopic balloon dilation for stenotic lesions in Crohn's disease. Turk J Gastroenterol 2017; 28: $117-124$

[130] Despott E], Gupta A, Burling D et al. Effective dilation of small-bowel strictures by double-balloon enteroscopy in patients with symptomatic Crohn's disease (with video). Gastrointest Endosc 2009; 70: 1030-1036

[131] Al-Bawardy B, Gorospe EC, Alexander JA et al. Outcomes of doubleballoon enteroscopy-assisted direct percutaneous endoscopic jejunostomy tube placement. Endoscopy 2016; 48: 552-556

[132] Bernardes C, Pinho R, Rodrigues A et al. Direct percutaneous endoscopic jejunostomy using single-balloon enteroscopy without fluoroscopy: a case series. Rev Esp Enferm Dig 2017; 109: 679-683

[133] Despott E], Gabe S, Tripoli E et al. Enteral access by double-balloon enteroscopy: an alternative method of direct percutaneous endoscopic jejunostomy placement. Dig Dis Sci 2011; 56: 494-498

[134] Serrano M, Mão-de-Ferro S, Pinho R et al. Double-balloon enteroscopy in the management of patients with Peutz-Jeghers syndrome: a retrospective cohort multicenter study. Rev Esp Enferm Dig 2013; 105: 594-599

[135] Rahmi G, Samaha E, Vahedi K et al. Multicenter comparison of double-balloon enteroscopy and spiral enteroscopy. J Gastroenterol Hepatol 2013; 28: 992-998

[136] Wadhwa V, Sethi S, Tewani S et al. A meta-analysis on efficacy and safety: single-balloon vs. double-balloon enteroscopy. Gastroenterol Rep (Oxf) 2015; 3: 148-155

[137] Williamson JB, Judah JR, Gaidos JK et al. Prospective evaluation of the long-term outcomes after deep small-bowel spiral enteroscopy in patients with obscure GI bleeding. Gastrointest Endosc 2012; 76: 771-778
[138] Aktas H, Mensink PB, Haringsma J et al. Low incidence of hyperamylasemia after proximal double-balloon enteroscopy: has the insertion technique improved? Endoscopy 2009; 41: 670-673

[139] Chen WG, Shan GD, Zhang $H$ et al. Double-balloon enteroscopy in small bowel diseases: Eight years single-center experience in China. Medicine (Baltimore) 2016; 95: e5104

[140] Gill RS, Kaffes AJ. Small bowel stricture characterization and outcomes of dilatation by double-balloon enteroscopy: a single-centre experience. Therap Adv Gastroenterol 2014; 7: 108-114

[141] Holleran G, Hall B, Breslin N et al. Long-acting somatostatin analogues provide significant beneficial effect in patients with refractory small bowel angiodysplasia: Results from a proof of concept open label mono-centre trial. United European Gastroenterol J 2016; 4: 70-76

[142] Chetcuti Zammit S, Sidhu R, Sanders D. Refractory anaemia secondary to small bowel angioectasias - comparison between endotherapy alone versus combination with somatostatin analogues. J Gastrointestin Liver Dis 2017; 26: 369-374

[143] Robles EP, Delgado PE, Conesa PB et al. Role of double-balloon enteroscopy in malignant small bowel tumors. World J Gastrointest Endosc 2015; 7: 652-658

[144] Ding NS, Yip WM, Choi CH et al. Endoscopic dilatation of Crohn's anastomotic strictures is effective in the long term, and escalation of medical therapy improves outcomes in the biologic era. J Crohns Colitis 2016; 10: 1172-1178

[145] Bettenworth D, Gustavsson A, Atreja A et al. A pooled analysis of efficacy, safety, and long-term outcome of endoscopic balloon dilation therapy for patients with stricturing Crohn's disease. Inflamm Bowel Dis 2017; 23: 133-142

[146] Tsuboi A, Oka S, Aoyama K et al. Artificial intelligence using a convolutional neural network for automatic detection of small-bowel angioectasia in capsule endoscopy images. Dig Endosc 2020; 32: 382-390

[147] Ding Z, Shi H, Zhang H et al. Gastroenterologist-level identification of small-bowel diseases and normal variants by capsule endoscopy using a deep-learning model. Gastroenterology 2019; 157: 10441054 e1045

[148] Dumonceau JM, Hassan C, Riphaus A et al. European Society of Gastrointestinal Endoscopy (ESGE) Guideline Development Policy. Endoscopy 2012; 44: 626-629

\section{CORRECTION}

Curriculum for small-bowel capsule endoscopy and device-assisted enteroscopy training in Europe: European Society of Gastrointestinal Endoscopy (ESGE) Position Statement

Sidhu R, Chetcuti Zammit S, Baltes P et al. Endoscopy 2020; 52: doi: 10.1055/a-1185-1289

In the above-mentioned article, the name of Stefania Chetcuti Zammit has been corrected.

This was corrected in the online version on June 26, 2020. 